\title{
A proteomic study of mesenchymal stem cells from equine umbilical cord
}

\author{
Leandro Maia a, b, *, Carolina Nogueira de Moraes a, Marianne Camargos Dias a , \\ Julia Bauzá Martinez ${ }^{\mathrm{b}}$, Antonia Odena Caballol ${ }^{\mathrm{b}}$, Giorgia Testoni ${ }^{\mathrm{c}}$, \\ Carla Martins de Queiroz ${ }^{a}$, Ramón Díaz Peña ${ }^{b}$, Fernanda C. Landim-Alvarenga ${ }^{a}$, \\ Eliandre de Oliveira ${ }^{\mathrm{b}}$
}

\author{
${ }^{a}$ Department of Animal Reproduction and Veterinary Radiology, School of Veterinary Medicine and Animal Science, São Paulo State University UNESP, \\ Botucatu, São Paulo 18618-681, Brazil \\ ${ }^{b}$ Proteomics Platform, Parc Cientific de Barcelona (PCB), Barcelona 08028, Spain \\ ${ }^{\mathrm{c}}$ Institute for Research in Biomedicine (IRB), Barcelona 08028, Spain
}

\section{A R T I C L E I N F O}

\section{Article history:}

Received 25 January 2017

Received in revised form

20 May 2017

Accepted 20 May 2017

Available online 24 May 2017

\section{Keywords:}

Proteomics

Protein

Horse

MSCs

Mass spectrometry

\begin{abstract}
A B S T R A C T
To the best of our knowledge, this is the first study describing the proteome of equine umbilical cord intervascular matrix mesenchymal stem cells (UCIM-MSCs) in a global and functional manner. The aim of this work was to analyze the proteome of previously characterized UCIM-MSCs to determine protein abundance and classify the identified proteins according to Gene Ontology (GO) terms. Protein classification analysis according to biological process, molecular function and cellular component was performed using the PANTHER (Protein ANalysis THrough Evolutionary Relationships) Classification System, which revealed enrichment for 42 biological processes, 23 molecular functions and 18 cellular components. Protein abundance was estimated according to the emPAI method (Exponential Modified Protein Abundance Index). The two most abundant proteins in the proteome of UCIM-MSCs were the cytoskeletal proteins actin and vimentin, which have important roles in cell stability and motility. Additionally, we identified 14 cell surface antigens. Three of them, CD44, CD90 and CD105, had been previously validated by flow cytometry. In the present study, we also identified important information about the biological properties of UCIM-MSCs such as differentiation potential, low immunogenicity (low MHC-II expression) and chromosomal stability, which reinforces their use for cell therapy. Together with the proteomic findings, this information allowed us to infer the functional relevance of several activities related to primary metabolic processes, protein synthesis, production of vesicle coats, vesicle-mediated transport and antioxidant activity. In addition, the identification of different cell surface markers may help establish an immunophenotypic panel suitable for the characterization of MSCs from equine fetal membranes.
\end{abstract}

๑) 2017 Elsevier Inc. All rights reserved.

\section{Introduction}

Mesenchymal stem cells (MSCs) have emerged as promising candidates for cell therapy given their numerous biological proprieties and benefits. The safety and feasibility of MSC

\footnotetext{
* Corresponding author. Department of Animal Reproduction and Veterinary Radiology, School of Veterinary Medicine and Animal Science, São Paulo State University UNESP, Botucatu, Street: Prof. Doutor Walter Mauricio Correa, w/n, 18618-681, Brazil.

E-mail address: leandromvet@hotmail.com (L. Maia).
}

transplantation [1], as well as satisfactory therapeutic responses, have been demonstrated in the literature for equine species [2,3].

In equine medicine, MSCs from bone marrow (BM-MSCs) and adipose tissue (AT) are considered the two most common types of adult stem cells (ASC) used in tissue regeneration [4] and in vitro studies. However, other sources of SCs such as fetal membranes (FM), including the umbilical cord (UC), have attracted great interest in the scientific community because their differentiation potency lies between that of embryonic stem cells and multipotent ASCs. Moreover, FM-derived SCs are also more ethically acceptable in human medicine and are thus attractive for regenerative 
therapies and biotechnological applications [5].

Proteins are key cellular components and have several features that cannot be predicted from their genetic sequences or transcription levels. For example, post-translational modifications, protein-protein interactions, and subcellular location can all affect protein function and activity [6]. Proteins play broad and complex roles in biological processes, and every step of cell generation, from DNA replication to senescence and death, depends on correct protein function [7]. Proteomics can be defined as the direct qualitative and quantitative analysis of all the proteins in an organism, tissue or cell under a given set of environmental and physiological conditions [8].

Many of the open questions in basic and clinical SC research can be answered most efficiently with proteomic analysis [6]. For example, proteomics can be used to study global protein profiles, the processes of differentiation and maturation, and the production of paracrine and autocrine factors [9]. In humans, the identification of protein markers may be useful for characterization, monitoring the differentiation and proliferation of MSCs, thus contributing to the discovery of therapeutic targets [10]. Likewise, such information when obtained through proteomic studies may contribute to the clinical application of MSCs in veterinary medicine.

Proteomic studies in equine medicine are still lacking, especially in the SC field. To the best of our knowledge, this is the first study to describe the proteome of equine umbilical cord mesenchymal stem cells in a global and functional manner by Gene Ontology (GO) classification. The aim of this work was to perform shotgun proteomic analysis on protein extracts from previously characterized mesenchymal stem cells from the intervascular matrix of equine umbilical cord and to classify the identified proteins according to GO terms. In addition, a semi-quantitative (Exponential Modified Protein Abundance Index) emPAI [11] analysis was performed to estimate the concentrations of the most abundant and particularly interesting proteins in the MSC proteome. These results will contribute to a better understanding of the biological properties of MSCs from fetal membranes. Additionally, proteins identified in the proteome of UCIM-MSCs, as well as their functional analysis are of great value for the directing of the cellular therapy in function of the clinical disorder and affected tissue. They will also lead to the identification of new biomarkers, thereby improving the characterization and therapeutic applications of equine MSCs.

\section{Materials and methods}

The experimental protocol (34/2013-CEUA) was approved by the ethics and welfare committee of Sao Paulo State University Botucatu.

\subsection{Collection of umbilical cord}

Equine UC samples $(\mathrm{N}=6)$ were collected at a thoroughbred farm. A segment of UC approximately $10 \mathrm{~cm}$ in length was collected and washed with phosphate-buffered saline (PBS), pH 7.4, containing antibiotics (1\%) and an antimycotic (1.2\%). Then, the samples were transferred into a $50-\mathrm{mL}$ tube containing medium composed of DMEM (Dulbecco's Modified Eagle's Medium) high glucose ( $4.5 \mathrm{~g} / \mathrm{L}$ ), 20\% fetal bovine serum (FBS), penicillin (100IU/ $\mathrm{mL})$, streptomycin $(100 \mathrm{mg} / \mathrm{mL})$ and amphotericin $(3 \mu \mathrm{g} / \mathrm{mL})$ (Thermo Fisher Scientific ${ }^{\circledR}$, USA) and were stored and transported at $5{ }^{\circ} \mathrm{C}$ in a refrigerated transport system (Botutainer ${ }^{\circledR}$, Botupharma, BRA).

\subsection{Isolation and culture of UCIM-MSCS}

The UC samples were first immersed in $70 \%$ ethanol $[12,13]$ and then washed in HBSS with penicillin/streptomycin (1\%), amphotericin B (1.2\%) (Thermo Fisher Scientific ${ }^{\mathbb{R}}$, USA) and amikacin (22 $\mu \mathrm{g} / \mathrm{mL})$. Subsequently, the UCs were dissected for complete removal of blood vessels, and the intervascular portion of the matrix was separated, fragmented, and digested with $1 \mathrm{mg} / \mathrm{mL}$ collagenase (Sigma-Aldrich ${ }^{\circledR}$, USA) at $37^{\circ} \mathrm{C}$. After enzymatic digestion, the samples were filtered through a $70-\mu \mathrm{m}$ filter (Becton Dickinson and Company ${ }^{\circledR}$, USA) and subsequently centrifuged with DMEM low glucose $(1 \mathrm{~g} / \mathrm{L})$ at a ratio of $1: 1$ at $350 \mathrm{~g}$ for $10 \mathrm{~min}$. Then, the supernatant was discarded and the pellet was resuspended and cultured in DMEM high glucose (4.5 g/L), 20\% fetal bovine serum, penicillin $(100 \mathrm{IU} / \mathrm{mL})$, streptomycin $(100 \mu \mathrm{g} / \mathrm{mL})$, amphotericin B $(3 \mu \mathrm{g} / \mathrm{mL})$ (Thermo Fisher Scientific ${ }^{\circledR}$, USA) and amikacin $(11 \mu \mathrm{g} / \mathrm{mL})$ (Teuto ${ }^{\circledR}, \mathrm{BRA}$ ) at $37.5^{\circ} \mathrm{C}$ in a humidified atmosphere containing $95 \%$ air and $5 \% \mathrm{CO}_{2}$. The maintenance medium was changed every 2 or 3 days until cell confluency reached at least $80 \%$, at which point cells were trypsinized to obtain subcultures for characterization and protein extraction.

\subsection{Assay for cellular differentiation into mesodermal lineages}

Second passage (2P) UCIM-MSCs $(\mathrm{N}=6)$ were seeded in sixwell plates (Sarstedt ${ }^{\mathbb{R}}$, USA) with maintenance medium. Fortyeight hours after incubation, the medium was removed and replaced with STEMPRO ${ }^{\circledR}$ osteogenic or adipogenic differentiation medium (Thermo Fisher Scientific ${ }^{\circledR}$, USA) according to the manufacturer's recommendations. Adipogenic and osteogenic media were supplemented with 5\% rabbit serum [14] and 20\% FBS [15], respectively.

Differentiation medium was changed every two to three days and confirmation of osteogenic and adipogenic differentiation were performed, respectively, by the observation of calcified extracellular matrix deposits using $2 \%$ Alizarin red staining, pH 4.2 (SigmaAldrich ${ }^{\circledR}$, USA), and the presence of intracytoplasmic lipids droplets using $0.5 \%$ Oil Red O (Sigma-Aldrich ${ }^{\circledR}$, USA). We note that for one sample, cell detachment prevented the evaluation of adipogenic differentiation.

\subsection{Flow cytometry analysis}

Immunophenotypic analysis was performed in second passage (2P) UCIM-MSCs $(\mathrm{N}=6)$ according to the methods described by Maia et al. [14] with modifications. Characterization was performed using a LSRFORTESSA flow cytometer (Becton Dickinson and Company ${ }^{\circledR}$, USA) with monoclonal antibodies anti-horseCD44 (clone CVS18, AbD Serotec $^{\circledR}$, USA), anti-horse MHC class II (CVS20, AbD Serotec ${ }^{\mathbb{R}}$, USA), anti-rat CD90 (clone OX7, AbD Serotec ${ }^{\circledR}$, USA), anti-human CD34 (clone 581/CD34, Becton Dickinson and Company ${ }^{\circledR}$, USA) and anti-human CD105 (clone SN6, AbD Serotec $^{\circledR}$, USA) antibodies labeled with fluorescein isothiocyanate. During the analyses, 10.000 events were recorded. The results were presented as the mean and standard error of the mean.

\subsection{Colony-forming unit fibroblastic assay (CFU-F)}

The self-renewal capacity and efficiency of UCIM-MSCs $(\mathrm{N}=6)$ was evaluated using the CFU-F assay, in triplicate, according to the methodology described by Mensing et al. [16] with modifications (seeding density and culture period were determined based on preliminary pilot studies). The UCIM-MSCSs (2P) were plated at a low density (2000 cells/well) in six-well plates. On day 5 , the cultures were fixed and stained with $1 \%$ violet crystal in methanol. Stained colonies with more than 20 cells were classified as CFU-F and counted. The colony-forming efficiency was calculated using the following formula: CFU-F = efficiency (CFU-F counted/seeding 
density) $\mathrm{x} 100$. The results were presented as the mean and standard error of the mean.

\subsection{Cytogenetic analysis}

Karyotype analysis was performed in $2 \mathrm{P}$ cells $(\mathrm{n}=6)$ synchronized by addition of a $0.0016 \%$ methotrexate (MTX)/thymidine (Tdi)/colchicine solution. For slide preparation, the cells were trypsinized at $37^{\circ} \mathrm{C}$, followed by addition of a hypotonic solution $(7.5 \mathrm{mM} \mathrm{KCl})$, fixation in a methanol/acetic acid solution $(3: 1, \mathrm{v} / \mathrm{v})$, washing $(1 \mathrm{x})$, staining with a $5 \%$ Giemsa solution, and light microscopy analysis. For each sample, 12 metaphase spreads were analyzed [14].

\subsection{Protein extraction}

UCIM-MSC suspensions ( $\mathrm{N}=3$ biological replicates) were centrifuged at $700 \mathrm{~g}$ at $4{ }^{\circ} \mathrm{C}$ (Eppendorf, USA) for $5 \mathrm{~min}$ in a solution containing $40 \mathrm{mM}$ Tris- $\mathrm{HCl}(\mathrm{pH}=7.4), 0.8 \mathrm{mM}$ EDTA ( $\mathrm{pH}=8.0)$, and a protease inhibitor cocktail (aprotinin, leupeptin, PMSF; SigmaAldrich $^{\circledR}$, USA). This procedure was performed three times to ensure the removal of FBS-derived proteins present during cell culture. Next, $150 \mu \mathrm{L}$ of lysis buffer $2.2 \mathrm{M}$ thiourea, $8 \mathrm{M}$ urea, $4 \%$ CHAPS [17], containing a protease inhibitor cocktail were added to the cell pellet. Prior to sonication, the samples were vortexed and packed into a container with ice flakes. Ten sonication cycles using the pulse mode ( $30 \mathrm{~s}$ sonication; $60 \mathrm{~s}$ stop) were performed. After sonication, the lysate was vortexed and centrifuged at 15,000 g at $4{ }^{\circ} \mathrm{C}$ for $30 \mathrm{~min}$. The subsequent protein extract was stored at $-86{ }^{\circ} \mathrm{C}$.

\subsection{Protein digestion}

Protein sample concentrations were quantified using the Pierce $660 \mathrm{~nm}$ Protein Assay (Thermo Fisher Scientific ${ }^{\circledR}$, USA). Then, $35 \mu \mathrm{g}$ of each sample was digested with trypsin using the FASP (FilterAided Sample Prep) digestion approach [18], with modifications. Briefly, samples were diluted to $450 \mu \mathrm{L}$ with a solution containing $50 \mathrm{mM}$ ammonium bicarbonate $(\mathrm{AB})$ and $8 \mathrm{M}$ urea. Samples were then immediately reduced with $5 \mathrm{mM}$ tris (2-carboxyethyl) phosphine (TCEP; Sigma-Aldrich ${ }^{\circledR}$, USA, \#C4706) (90 min at $32^{\circ} \mathrm{C}$ ), and alkylated with $30 \mathrm{mM}$ iodoacetamide (IAA; room temperature, RT, for $30 \mathrm{~min}$ in the dark). Next, samples were loaded onto a $10 \mathrm{kDa}$ Amicon Ultra filter $\left(0.5 \mathrm{~mL}\right.$, Millipore $\left.{ }^{\circledR}, \mathrm{USA}\right)$ to remove interfering compounds by means of 3 rounds of centrifugation $(13,000 \mathrm{~g}$, $20 \mathrm{~min}, \mathrm{RT})$ and washes ( $300 \mu \mathrm{L}$ of $50 \mathrm{mM} \mathrm{AB}, \mathrm{pH}$ 8.0-8.5). Then, proteins were double digested with Lys-C and porcine trypsin in $400 \mu \mathrm{L}$ of the same exchange buffer plus $1 \mathrm{M}$ urea (digest 1 : Sequencing-grade endoproteinase Lys-C, Promega; $1.6 \mu \mathrm{g}$ Lys-C/ sample; $35^{\circ} \mathrm{C}, \mathrm{pH} 8.5,2 \mathrm{~h}$, and digest 2: Sequencing-grade modified trypsin, Promega; $1.6 \mu \mathrm{g}$ trypsin/sample; $35^{\circ} \mathrm{C}, \mathrm{pH} 8.5,16 \mathrm{~h}$ ). The resulting peptide mixture was recovered by means of 4 rounds of centrifugation $(13,000 \mathrm{~g}, 20 \mathrm{~min}, \mathrm{RT})$ and washes $(2 \times 300 \mu \mathrm{L}$ of $50 \mathrm{mM} \mathrm{AB} ; 1 \times 300 \mu \mathrm{L}$ of $20 \%$ acetonitrile, $\mathrm{ACN}$ ), dried down in a vacuum centrifuge system and stored at $-20{ }^{\circ} \mathrm{C}$. Before LC-MS/MS analysis, impurities were removed using a C18 tip (reverse phase, P200 TopTip C18, PolyLC ${ }^{\circledR}$, USA) and a strong cationic exchange tip (P200 TopTip, PolySULFOETHYL A, PolyLC ${ }^{\mathbb{R}}$, USA). Samples were then dried down in a vacuum centrifuge.

\subsection{Mass spectrometry analysis}

Samples ( $N=3$ biological replicates, each with 3 technical replicates) were analyzed in a nanoAcquity liquid chromatographer (Waters ${ }^{\circledR}$, USA) coupled to a LTQ-Orbitrap Velos (Thermo Fisher
Scientific ${ }^{\circledR}$, USA) mass spectrometer. The peptides were resuspended in 1\% FA solution and an aliquot (500 ng) was injected for chromatographic separation. Peptides were trapped on a Symmetry C18 ${ }^{\mathrm{TM}}$ trap column ( $5 \mu \mathrm{m}, 180 \mu \mathrm{m}$ Øi x $20 \mathrm{~mm}$; Waters) and were separated using a C18 reverse phase capillary column $(75 \mu \mathrm{m} \mathrm{Øi,}$ $25 \mathrm{~cm}, 1.7 \mu \mathrm{m}$ BEH column; Waters). The gradient used for the elution of the peptides was 2-35\% B in 155 min, followed by $35 \%-$ $45 \% \mathrm{~B}$ in $20 \mathrm{~min}$ (A: 0.1\% FA; B: 0.1\% FA in ACN), with a $250 \mathrm{~nL} / \mathrm{min}$ flow rate.

Eluted peptides were subjected to electrospray ionization in an emitter needle (PicoTip ${ }^{\mathrm{TM}}$, New Objective) with an applied voltage of $2000 \mathrm{~V}$. Peptide masses $(\mathrm{m} / \mathrm{z} 300-1800)$ were analyzed in datadependent mode where a full Scan MS in the Orbitrap with a resolution of 60,000 FWHM at $400 \mathrm{~m} / z$ was obtained. Up to 15 of the most intense signals (minimum intensity of 500 counts) were selected from each MS scan and fragmented using CID (38\% normalized collision energy) in the linear ion trap with helium as the collision gas. Raw data were collected with Thermo Xcalibur (v.2.2).

\subsection{Data analysis}

Thermo Proteome Discover (v.1.4.1.14) software and the SequestHT search engine were used to search the UniProt Equus protein database (v. February 2016) and identify contaminants. The search parameters used were: Enzyme Name: Trypsin; Missed Cleavage Sites: 2; Precursor Mass Tolerance: 10 ppm; Fragment Mass Tolerance: $0.6 \mathrm{Da}$; Variable Modification: Oxidation of methionine; Static Modification: Carbamidomethyl of cysteine.

\subsection{Determination of protein abundance (emPAI and protein content in mol\%)}

Quantification was performed by emPAI analysis using protein identification data from Mascot search engine v. 1.3. The same search parameters described above were used to calculate the emPAI and protein content in mol\% according to the emPAI $\left(10^{\mathrm{PAI}}-1\right)$ method, in which PAI (Protein Abundance Index) is the number of identified peptides divided by the observable number of peptides per protein. The equation emPAI/ $\Sigma$ (emPAI) x 100 [11] was used to calculate the protein content in mol\%.

\subsection{Gene Ontology classification analysis}

Protein classification analysis according to biological process (BP), molecular function (MF) and cellular component (CC) was performed using Gene Ontology and the PANTHER (Protein ANalysis THrough Evolutionary Relationships) Classification System (http://pantherdb.org/).

\subsection{Western blotting}

For Western blotting, $5 \mu \mathrm{g}$ of proteins from cell lysates were loaded in a 10\% SDS-PAGE gel and transferred to immobilon membranes (Millipore ${ }^{\circledR}$, USA). The membrane was blocked with 3\% (wt/vol) bovine serum albumin (BSA) (Sigma- Aldrich ${ }^{\circledR}$, USA) and then probed using the following primary antibodies: mouse antibody against Vimentin Clone V9 (Boehringer Mannheim Corpora$\operatorname{tion}^{\circledR}$, USA) and a mouse antibody against actin (Sigma). Secondary antibodies conjugated with horseradish peroxidase against mouse immunoglobulines (Dako ${ }^{\circledR}$, USA). Bands were visualized using Immobilon Western Chemiluminescent HRP Substrate (Millipore ${ }^{\mathbb{R}}$, USA). 


\subsection{Vimentin and CD44 immunocytochemistry}

Immunocytochemistry analysis ( $\mathrm{N}=2$ biological replicates) was performed on 24-well plates (Sarstedt ${ }^{\circledR}$, USA) using mouse antivimentin $\left(1: 50\right.$, V9, Dako Cytomation $\left.{ }^{\circledR}, \mathrm{DNK}\right)$ and mouse antihorse CD44 (1:100, CVS18, AbD Serotec ${ }^{(}$, UK) antibodies according to methodology described by our group [14] with modifications. The use of the anti-vimentin antibody was based on the crossreactivity of clone $\mathrm{v} 9$ observed in a previous study [14].

\section{Results}

\subsection{Culture and characterization of UCIM-MSCS}

Mesenchymal stem cells were obtained from the intervascular matrix of six equine umbilical cords. Cells adhered to plastic dishes within 24-48 h, and cell confluence was achieved between the eighth and fifteenth days of culture. Cells in primary culture (PC), the first passage (1P) and the second passage (2P) showed predominantly fibroblastoid morphology.

Immunophenotyping analysis revealed high expression levels of $\mathrm{CD} 44(\bar{x}=83.2 \pm 9.8 \%)$ and low expression of $\operatorname{CD} 90(\bar{x}=27 \pm 7.3 \%)$ and $\operatorname{CD} 105(\bar{x}=11 \pm 5.3 \%)$. On the other hand, CD34 $(\bar{x}=1.36 \pm 0.48 \%)$ and MHCII $(\bar{x}=2.9 \pm 0.7 \%)$ expression was not observed.

The differentiation potential was demonstrated for adipogenic and osteogenic lineage after eight or ten days of culture with medium of differentiation, respectively. Cells differentiated into adipogenic lineage presented medium to large fat droplets points (Fig. 1a) and differentiated into osteogenic lineage presented abundant deposition of a calcium-rich extracellular matrix (Fig. 1c).

UCIM-MSCs exhibited an average CFU-F efficiency of $10 \pm 1.27 \%$. Moreover, in karyotype analyses, $100 \%$ of metaphases investigated exhibited chromosomal stability with normal chromosome numbers for equine species $(2 \mathrm{n}=64)$ in $2 \mathrm{P}$ cells.

\subsection{Proteomic analysis of UCIM-MSCS}

Proteomic analysis was carried out in three biological replicates. Protein extracts were enzymatically digested using the FASP methodology [18] with modifications, including a 2-h digestion with Lys-C and an overnight digestion with modified porcine trypsin. Moreover, three technical replicates were performed for each biological replicate. Then, data from 9 LC-MS/MS were combined to obtain the results shown below. As shown in Fig. 2 and 3559 protein groups were identified, 2118 of which were identified with at least two peptide sequences per protein (false discovery rate lower than $1 \%$, FDR $<1 \%$ ).

To quantitate the abundance of the identified proteins, we calculated the Exponential Modified Protein Abundance Index (emPAI) using the MASCOT search engine (Matrix Sciences, London, UK). emPAI allows for estimation of the relative protein abundance in complex samples, and it is calculated by taking into account the number of observed peptides from the Mascot search engine and a user-configurable identification threshold. The theoretical number of peptides (observable peptides) is aggregated from appropriate protein databanks, and the peptides are filtered according to their molecular weight (MW) and the predicted LC retention times. The emPAI is calculated with the formula: emPAI $=10^{\text {(observed peptides)/ }}$ (observable peptides) -1 . The protein content ( $\mathrm{mol} \%$ ) of the proteins was calculated for each replicate and the results are presented as the mean value of the three replicates. The mean protein contents for the 10 most abundant proteins are shown in Table 1 . The most abundant proteins are cytoskeletal components such as actin and vimentin, which have important roles in cell stability and motility.

In addition, we identified 14 cell surface antigens in the UCIM-
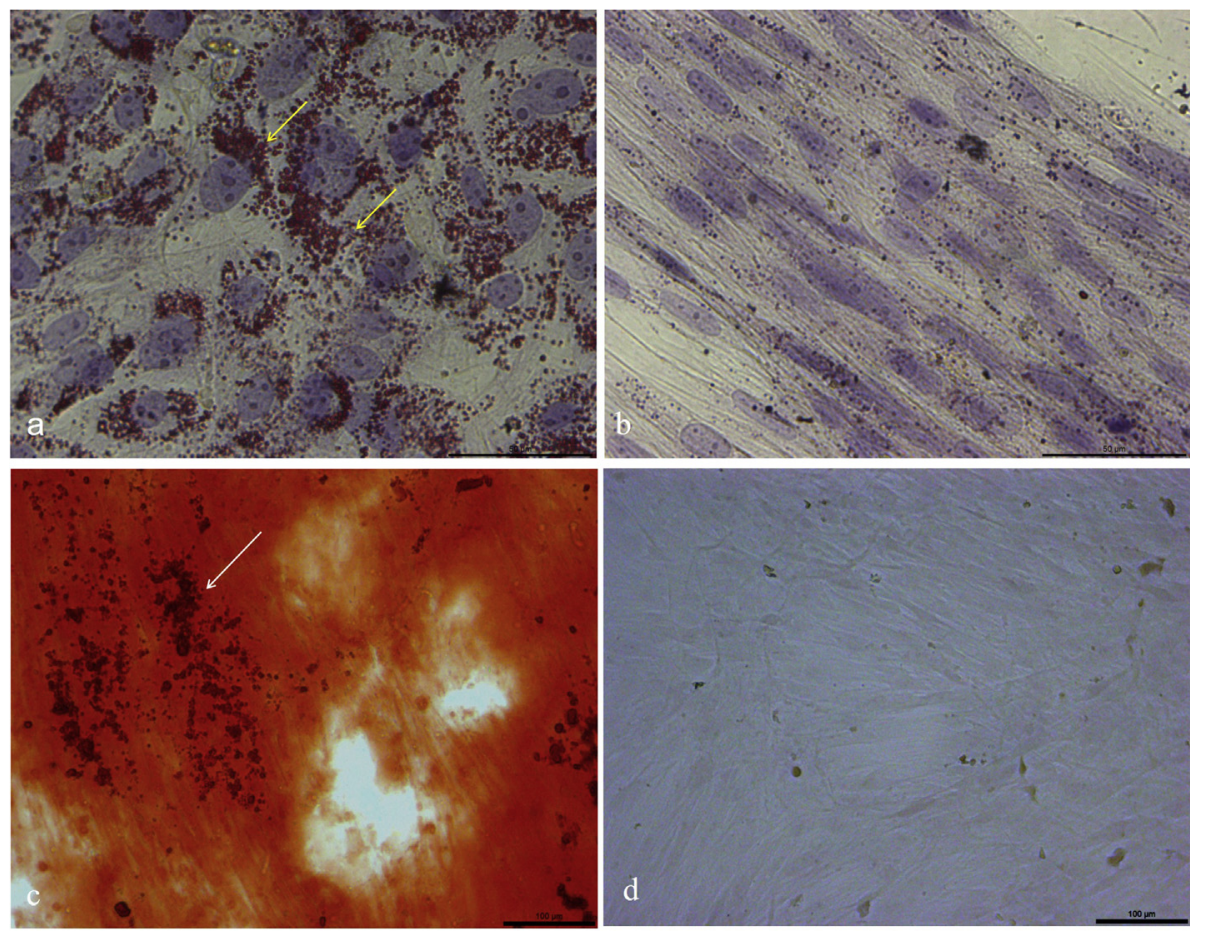

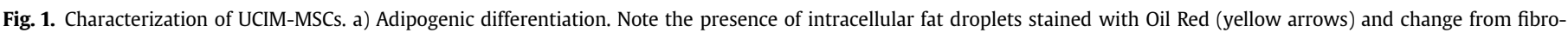

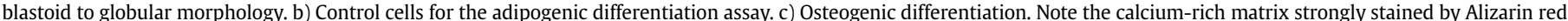

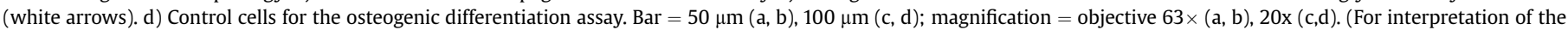
references to colour in this figure legend, the reader is referred to the web version of this article.) 

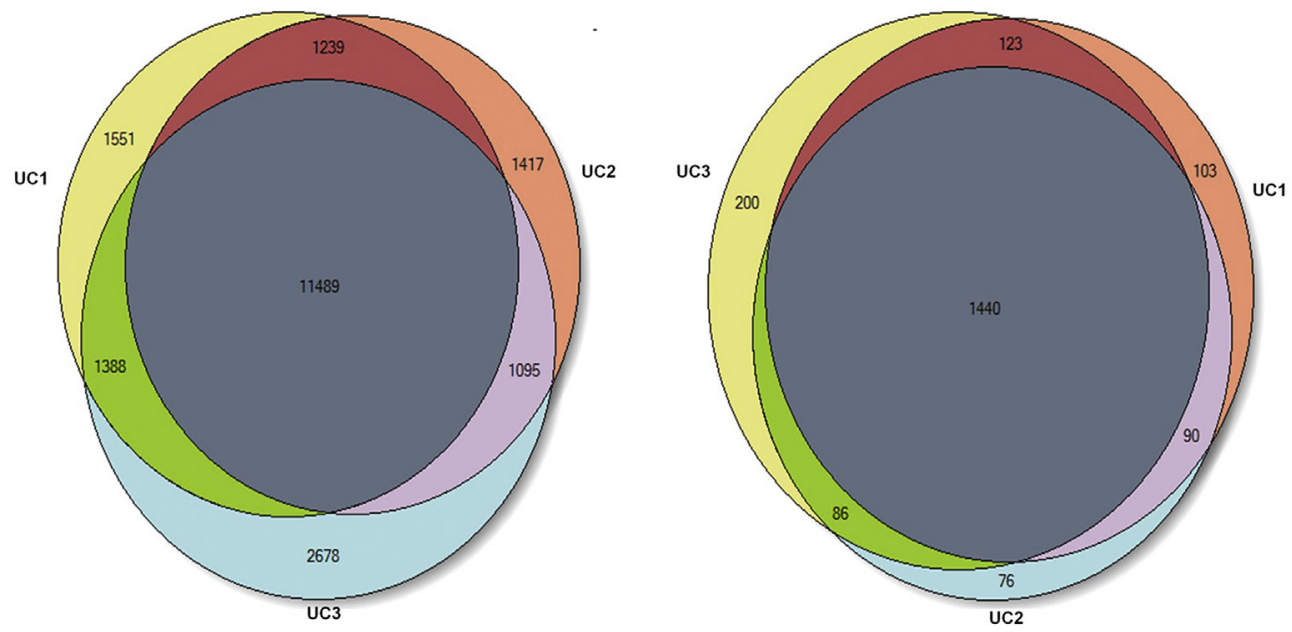

Fig. 2. Venn Diagrams for peptides (a) and proteins (b) identified by shotgun proteomics with at least two peptide sequences (FDR $<1 \%$ ) in the three replicates.

MSC proteome (Table 2). The antigens CD44, CD90 and CD105 were validated by flow cytometry. Additionally, we also observed the expression of numerous growth factors and receptors, as shown in Table 2.

To better characterize the UCIM-MSC proteome, we classified the identified proteins using Gene Ontology terms (http:// geneontology.org/). The PANTHER GO analysis indicated that 42 biological processes (BP) were positively enriched in UCIM-MSCs, with positive fold enrichments (FE) ranging from 1.15 to $>5$. The most highly enriched BPs (FE $>5$ ) included the tricarboxylic acid cycle (GO:0006099), glycolysis (GO:0006096), nuclear transport (GO:0051169) and protein folding (GO:0006457). Interestingly, vesicle-mediated transport (GO:0016192; FE $=2.03$ ), which is associated with UCIM-MSC-mediated paracrine signaling through vesicle release, was also found to be enriched. In addition, the proteome of UCIM-MSCs was highly enriched for 23 molecular functions (MF) (FE from 1.32 to $>5$ ). The three most enriched MFs included aminoacyl-tRNA ligase activity (GO:0004812; FE > 5), peroxidase activity (GO: 0004601; $\mathrm{FE}=4.90$ ) and antioxidant activity (GO:0016209; FE $=4.55$ ). In relation to cellular component (CC), the proteome was positively enriched for 18 CCs (FE from 1.79 to $>5$ ). The most highly enriched CCs included vesicle coat (GO:0030120; FE > 5), ribosome (GO:0005840; FE > 5) and Golgi apparatus (GO:0005794; $\mathrm{FE}=4.70)$.
We also used immunocytochemistry to validate the expression and localization of two proteins identified in the nanoLC/MS/MS analysis, including vimentin (Fig. 3a) and the cell surface marker CD44 (Fig. 3b). Additionally, the analysis by Western blot also confirmed our proteomic results, as show in Fig. 4. Using a small protein concentration ( $5 \mu \mathrm{g}$ ) from the lysate of UCIM-MSCs, we observed a strong signal on the identification of the protein vimentin $(57 \mathrm{kDa})$.

\section{Discussion}

Our study clearly demonstrates that MSCs abundantly express cytoskeleton proteins, which may indicate efficient cell migration potential ("homing"). Another attractive property for cell therapy applications observed in the present study was the robust enrichment in antioxidant activity, which is fundamental for the prevention of free radical-induced cell damage.

UCIM-MSCs were properly characterized according to their morphological aspects, clonicity, chromosomal stability and potential to differentiate into mesodermal lineages. Immunophenotypic analysis of MSCs also demonstrated strong expression of CD44, and weak expression of CD105 and CD90. On the other hand, MHC II and CD34 were not expressed. These results confirm previous findings from our group in amniotic fluid MSCs [19] and are in

Table 1

List of the 10 most abundant proteins in UCIM-MSC lysates with mean protein content values (mol\%) and brief functional descriptions.

\begin{tabular}{|c|c|c|c|c|}
\hline $\begin{array}{l}\text { Swiss-Prot } \\
\text { accession }\end{array}$ & $\begin{array}{l}\text { Gene } \\
\text { name }\end{array}$ & Protein name & $\begin{array}{l}\text { Protein content (mol } \\
\%)\end{array}$ & Brief function \\
\hline F6T3Y8 & АСТВ & Actin, cytoplasmic 1 & 4.68 & ${ }^{\mathrm{a} C e l l}$ motility \\
\hline F7B5C4 & VIM & $\begin{array}{l}\text { Uncharacterized } \\
\text { protein }\end{array}$ & 3.58 & ${ }^{\mathrm{a}}$ Involved in the stabilization of type I collagen mRNAs for CO1A1 and CO1 \\
\hline A8J714 & TAGLN & Transgelin & 1.92 & ${ }^{\mathrm{a} A c t i n}$ cross-linking/gelling protein. \\
\hline F6QXN5 & TAGLN2 & $\begin{array}{l}\text { Transgelin } \\
\text { (Fragment) }\end{array}$ & 0.92 & - \\
\hline F6YAZ9 & MYL12A & $\begin{array}{l}\text { Uncharacterized } \\
\text { protein }\end{array}$ & 0.88 & 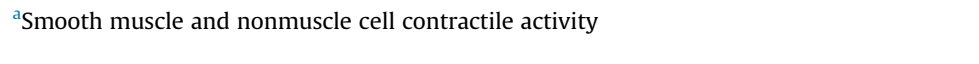 \\
\hline F7DYV0 & LGALS1 & Galectin & 0.76 & ${ }^{\text {a }}$ Plays a role in regulating apoptosis, cell proliferation and cell differentiation. \\
\hline F6VFV9 & HIST1H4D & Histone $\mathrm{H} 4$ & 0.73 & $\begin{array}{l}\text { Play a central role in transcription regulation, DNA repair, DNA replication and chromosomal } \\
\text { stability. }\end{array}$ \\
\hline B3IVM1 & PKM & Pyruvate kinase & 0.63 & Catalytic activity/Glycolysis \\
\hline Q8HZM6 & ANXA1 & Annexin A1 & 0.61 & Anti-inflammatory effect \\
\hline F6PWV8 & SERPINH1 & $\begin{array}{l}\text { Uncharacterized } \\
\text { protein }\end{array}$ & 0.58 & ${ }^{\mathrm{a}}$ Binds specifically to collagen \\
\hline
\end{tabular}

\footnotetext{
${ }^{\text {a }}$ Inference from BLAST against SwissProt mammals (http://www.uniprot.org/blast/). All proteins were identified with at least one unique peptide in at least two replicates.
} 
Table 2

List of cell surface antigens, growth factors and receptors identified in UCIM-MSC lysates.

\begin{tabular}{|c|c|c|c|c|}
\hline \multicolumn{5}{|l|}{ Cell surface antigens } \\
\hline SwissProt accession & $\begin{array}{l}\text { Gene } \\
\text { name }\end{array}$ & Protein name & Alternative name ${ }^{a}$ & $\begin{array}{l}\text { Frequency of observation at } \\
\mathrm{BR}^{\mathrm{b}}\end{array}$ \\
\hline F7B5L3 & ALCAM & Uncharacterized protein & CD166 & 3 \\
\hline A5JST8 & $\mathrm{N} / \mathrm{A}^{\mathrm{c}}$ & CD147 & CD147 & 3 \\
\hline F6WQJ4 & CD9 & Tetraspanin (Fragment) & CD9 & 3 \\
\hline F6Q9S8 & CD81 & Tetraspanin (Fragment) & CD81 & 1 \\
\hline F6PTV7 & CD44 & CD44 antigen & CD44 & 3 \\
\hline F7CEQ2 & CD63 & Tetraspanin & CD63 & 3 \\
\hline Q860N9 & $\mathrm{N} / \mathrm{A}$ & Putative classical MHC class I antigen & MHC-I & 1 \\
\hline B5AZR9 & THY1 & Thy-1 antigen (Fragment)] & CD90 & 2 \\
\hline F6ZQF7 & ICAM1 & Uncharacterized protein] & CD54 & 2 \\
\hline F6UR46 & ITGB1 & Integrin beta (Fragment) & CD29 & 3 \\
\hline F6SH38 & LAMP1 & Uncharacterized protein & CD107a & 3 \\
\hline Q2V905 & TFRC & Transferrin receptor protein 1 & CD71 & 3 \\
\hline F7B906 & SLC3A2 & Uncharacterized protein] & CD98 & 3 \\
\hline F6W046 & ENG & Uncharacterized protein & CD105 & 3 \\
\hline \multicolumn{5}{|c|}{ Growth factors and receptors } \\
\hline $\begin{array}{l}\text { SwissProt } \\
\text { accession }\end{array}$ & $\begin{array}{l}\text { Gene } \\
\text { name }\end{array}$ & Protein name & Blast name mammalian & $\begin{array}{l}\text { Frequency of observation at } \\
\text { BR }\end{array}$ \\
\hline F6ZN26 & HDGF & Uncharacterized protein & Hepatoma-derived growth factor & 3 \\
\hline F6TPM3 & TGFB1I1 & Uncharacterized protein & $\begin{array}{l}\text { Transforming growth factor beta-1-induced transcript } 1 \\
\text { protein }\end{array}$ & 3 \\
\hline F6VWA8 & IGF2R & Uncharacterized protein & Cation-independent mannose-6-phosphate receptor & 3 \\
\hline F6PIH8 & MYDGF & Uncharacterized protein & Myeloid-derived growth factor & 3 \\
\hline F6VB94 & TGFBI & Uncharacterized protein & Transforming growth factor-beta-induced protein ig-h3 & 1 \\
\hline Q5IF07 & IGFBP & $\begin{array}{l}\text { Insulin-like growth factor binding } \\
\text { protein-2 }\end{array}$ & - & 1 \\
\hline F6RV24 & IGF2BP1 & Uncharacterized protein & Insulin-like growth factor 2 mRNA-binding protein 1 & 1 \\
\hline F6XXS9 & IGF2BP3 & Uncharacterized protein & Insulin-like growth factor 2 mRNA-binding protein 3 & 1 \\
\hline F6Q748 & PDGFRB & Receptor protein-tyrosine kinase & Platelet-derived growth factor receptor beta & 2 \\
\hline
\end{tabular}

a Inference from BLAST against SwissProt mammals.

b BR: biological replicate.

c N/A: not applicable.
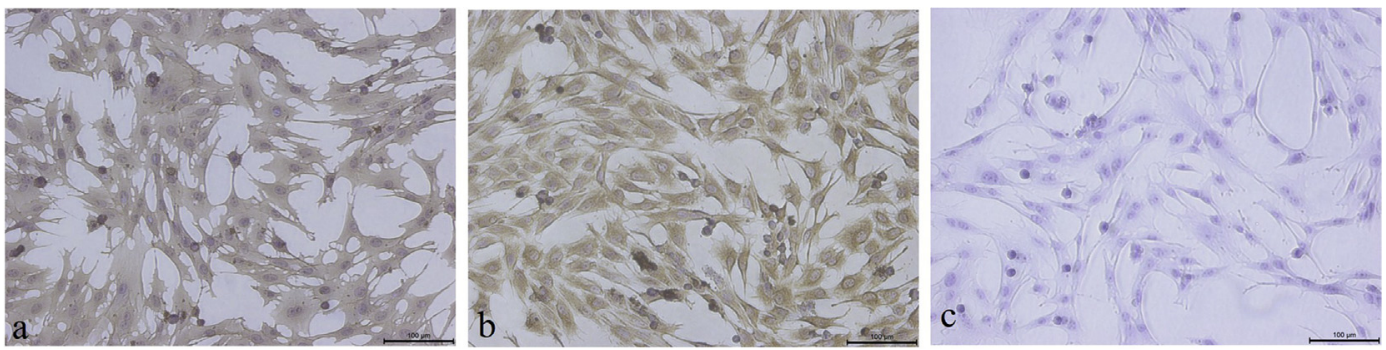

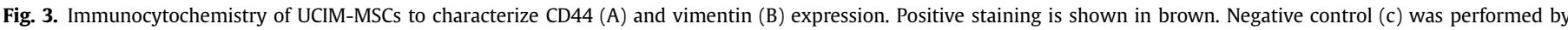

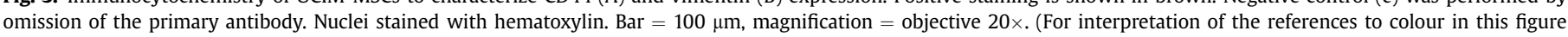
legend, the reader is referred to the web version of this article.)

accordance with studies of MSCs from the equine UC matrix $[20,21]$. It is important to emphasize that the immunophenotypic profiles of equine MSCs from different tissues are variable. Moreover, these markers are often distinct from the proposed panel for human MSCs.

Recently, Paebst et al. [22] used flow cytometry to analyze surface antigens (CD29, CD44, CD73, CD90, CD105, CD14, CD34, CD45, CD79a, and MHC II) in equine MSCs from bone marrow, umbilical cord tissue, tendon, umbilical cord blood and adipose tissue. They observed marked variations in the expression of CD105 and CD90. In MSC samples from umbilical cord tissue, the authors observed low expression of CD105 (6.75 $\pm 10.72 \%$ ) and no expression of CD90, which corroborates the low expression of these markers in our study. These results reaffirm the need to establish a more specific panel for immunophenotypic characterization of equine MSCs, particularly those from fetal membranes.

Recently, Marycz et al. [23], identified differences in the immunophenotypic profiles of adipose tissue MSCs from healthy horses and animals with metabolic syndrome (MS). The expression levels of CD90, CD105 and CD73 were significantly reduced in MSCs from equines with MS. However, the expression of CD44 did not change between the groups (healthy versus MS).

Using a shotgun approach to analyze the total proteome of UCIM-MSCs, we identified 14 surface antigens (Table 2). These results are in accordance with the findings of Niehage et al. [24] who identified a total of $41 \mathrm{CD}$ markers in membrane-enriched samples from bone marrow-derived human MSCs. We believe that some of the $\mathrm{CD}$ markers identified in our proteomic study, which have not been tested for immunological characterization, may be immunophenotypic marker candidates after proper validation. 


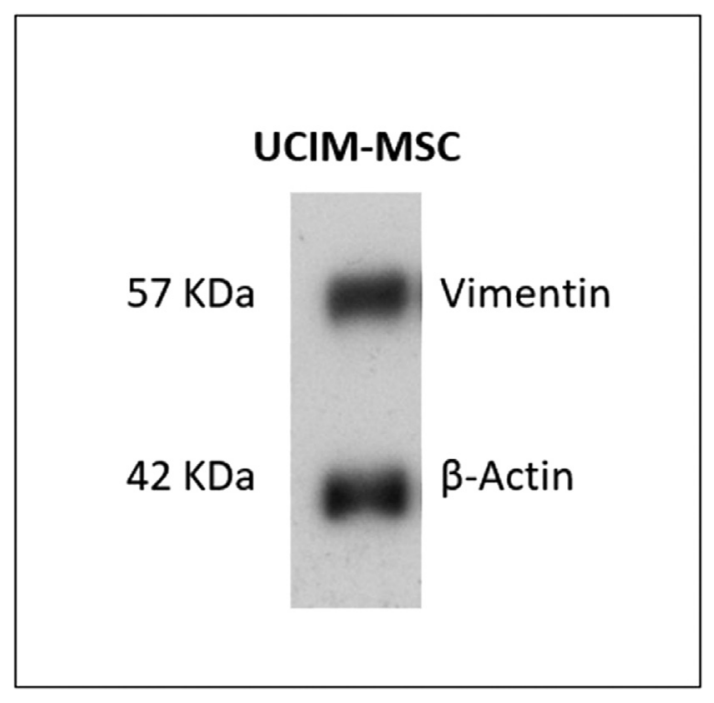

Fig. 4. Validation of the analysis of proteomic results by Western blotting. Identification of vimentin protein ( $57 \mathrm{kDa}$ ) and $\beta$-actin in equine UCIM-MSC lysates.

The results for the 10 most abundant proteins in the UCIM-MSC proteome revealed a predominance of cytoskeletal proteins (actin and vimentin), which are related to cell structure and contractile activity. A well-developed cytoskeleton associated with the expression of adhesion molecules (e.g., ICAM1/CD54) could significantly enhance the ability of UCIM-MSCs to migrate and home to sites of injury. Homing is the process by which cells migrate to and engraft into tissue, and would allow the MSCs to exert their local reparative effects on damaged tissue [25]. Recently, Huang et al. [26] demonstrated that vimentin plays an important role in the migration of UC-MSCs and BM-MSCs. These findings support our hypothesis that UCIM-MSCs could have significant migratory capacities. It is important to highlight that our group has already observed expression of this protein in equine MSCs from bone marrow [14] and amniotic fluid [19], a finding reinforced by mass spectrometry in the present study. Migratory potential is a highly desirable feature of MSCs, particularly with regard to systemic cell therapy applications.

Other important proteins identified in our study were growth factors from the TGF $\beta$ and IGF families, as well as galectin (LGALS1; the sixth most abundant protein). In a recent review, Konala et al. [27] reported that these proteins (TGF $\beta$, IGF, and galectin) could be present in the MSC secretome depending on the preconditioning factors (hypoxia/anoxia, genetic engineering, molecular, pharmacological and physical). Some of the known functions of these molecules include anti-apoptosis (TGF $\beta$ ), chemoattraction (IGF), proliferation (IGF), immunomodulation (TGF $\beta$ ), hematopoietic stem cell support (TGF $\beta$ ) and neuroprotection (galectin-1).

GO analysis of our data showed that UCIM-MSCs were enriched in antioxidant activity. This result was also reported in other in vitro [28] and in vivo $[28,29]$ studies, including a study of the antioxidant effects of canine MSCs in hepatocyte co-culture and an in vivo model of thioacetamide-induced liver injury. The authors observed MSC-induced hepatoprotective effects including reductions in the levels of reactive oxygen species and improvements in other evaluated parameters. These results corroborate our findings and reinforce the belief that UCIM-MSCs have great therapeutic potential for treating conditions associated with oxidative stress, such as ischemia-reperfusion injury, airway disease, equine motor neuron disease, osteoarthritis, equine Cushing's disease, endometritis [30] and laminar hoof oxidative stress [31].
The enrichment for vesicle coat and vesicle-mediated transport observed in GO term analysis may be associated with extracellular vesicle transport (exosomes and microvesicles) and paracrine signaling [32]. Extracellular vesicle production and secretion were identified by Pascucci et al. [33] in equine adipose tissue MSCs and were shown to be involved in the stimulation of angiogenesis. Another important property (anti-inflammatory activity) of extracellular vesicles produced by equine MSCs has recently been demonstrated in in vitro studies involving models of tenocytes [34] and endometrial cells [35].

\section{Conclusion}

The proteomic approach used in this study allowed a semiquantification of the main proteins that composes the proteome of equine UCIM-MSCs. The proteins identified and classified by GO analysis have important properties (eg, antioxidant activity, vesicle coat and vesicle-mediated transport), that reinforces the application of UCIM-MSCs at cell therapy. In addition, we identified several cell surface markers that may help in the establishment of an immunophenotypic panel more suitable for characterization of MSCs of equine fetal membranes.

\section{Acknowledgements}

To Fundação de Amparo à Pesquisa do Estado de São Paulo (Proc: 12/23888-4; Proc: 15/17619-9) and Pró-Reitoria de PesquisaUNESP for the postdoctoral scholarship. We are also thank to the ProteoRed-ISCIII, the Spanish Proteomics network.

\section{References}

[1] Alvarenga MA, Carmo MT, Segabinazzi LG, Guastali MD, Maia L, LandimAlvarenga FC. Feasibility and safety of endometrial injection of autologous bone marrow mesenchymal stem cells in mares. J Equine Vet Sci 2016;42: $12-8$.

[2] Nicpoń J, Marycz K, Grzesiak J. Therapeutic effect of adipose-derived mesenchymal stem cell injection in horses suffering from bone spavin. Pol J Vet Sci 2013;16:753-4.

[3] Ardanaz N, Vázquez FJ, Romero A, Remacha AR, Barrachina L, Sanz A, et al Inflammatory response to the administration of mesenchymal stem cells in an equine experimental model: effect of autologous, and single and repeat doses of pooled allogeneic cells in healthy joints. BMC Vet Res 2016;12:1-9.

[4] Vidal MA, Robinson SO, Lopez MJ, Paulsen DB, Borkhsenious Johnson JR, Moore RM, et al. Comparison of chondrogenic potential in equine mesenchymal stromal cells derived from adipose tissue and bone marrow. Vet Surg 2008;37:713-24.

[5] Cremonesi F, Corradetti B, Lange CA. Fetal adnexa derived stem cells from domestic animals: progress and perspectives. Theriogenology 2010;75: $1400-15$.

[6] Sung-Min A, Simpson R, Lee B. Genomics and proteomics in stem cell research: the road ahead. Anat Cell Biol 2010;43:1-14.

[7] Feist P, Hummom AB. Proteomic challenges: sample preparation techniques for microgram-quantity protein analysis from biological samples. Int J Mol Sci 2015; 16:3537-63.

[8] Fergunson PL, Smith RD. Proteome analysis by mass spectrometry. Annu Rev Biophys Biomol Struct 2003;32:399-424.

[9] Stastna M, Abraham MR, Van Eyk JE. Cardiac stem/progenitor cells, secreted proteins, and proteomics. FEBS Lett 2009;583. 1800-18007.

[10] Foster LJ, Zeemann PA, Li C, Mann M, Jense OL, Kassem M. Differential expression profiling of membranes proteins by quantitative proteomics in a human mesenchymal stem cells line undergoing osteoblast differentiation. Stem Cells 2005;23:1367-77.

[11] Ishihama Y, Oda Y, Tabata T, Sato T, Nagasu T, Rappsilber J, et al. Exponentially modified protein abundance index (emPAI) for estimation of absolute protein amount in proteomics by the number of sequenced peptides per protein. Mol Cell Proteomics 2005;4:1265-72.

[12] Iacono E, Brunori L, Pirrone A, Pagliaro PP, Ricci F, Tazzari PL, et al. Isolation, characterization and differentiation of mesenchymal stem cells from amniotic fluid, umbilical cord blood and Wharton's jelly in the horse. Reproduction 2012;143:311-25.

[13] De Schauwer C, Goossens K, Piepers S, Hoogewijs MK, Govaere JL, Smits K, et al. Characterization and profiling of immunomodulatory genes of equine mesenchymal stromal cells from non-invasive sources. Stem Cell Res Ther 2014;5:1-13. 
[14] Maia L, Alvarenga FCL, Mota LSLS, Golin MA, Laufer-Amorim R, de Vita B, et al. Immunophenotypic, immunocytochemistry, ultrastructural and cytogenetic characterization of mesenchymal stem cells from equine bone marrow. Microsc Res Tech 2013;76:618-24.

[15] Toupadakis CA, Woung A, Genetos DC, Cheung WK, Borjesson DL, Ferraro GL, et al. Comparison of the osteogenic potential of equine mesenchymal sten cells from bone marrow, adipose tissue, umbilical cord blood, and umbilical cord tissue. Am J Vet Res 2010;71:1237-45.

[16] Mensing N, Gasse H, Hambruch N, Haeger JD, Pfarrer C, Staszyk C. Isolation and characterization of multipotent mesenchymal stromal cells from the gingiva and the periodontal ligament of the horse. BMC Vet Res 2011;7:1-13.

[17] Paula LB. Proteomics analysis of the various stages of osteoblastic differentiation of mesenchymal stem cells form bone marrow. Ribeirão Preto, SP: USP 2010. 145p. (Master of Molecular and Cellular Biology ). Faculdade de Medicina de Ribeirão Preto, Universidade de São Paulo.

[18] Wisniewski JR, Zougman A, Nagaraj N, Mann M. Universal sample preparation method for proteome analysis. Nat Methods 2009;6:359-63.

[19] De Vita B, Campos LL, Listoni AJ, Maia L, Sudano MJ, Curcio BR, et al. Isolation, characterization and differentiation of mesenchymal stem cells derived from equine amniotic fluid obtained from different gestacional ages. Braz J Vet Res Anim 2013;33:535-42.

[20] Hoynowski SM, Fry MM, Gardner BM, Leming MT, Tucker JR, Black L, et al. Characterization and differentiation of equine umbilical cord-derived matrix cells. Biochem Biophys Res Commun 2007;362:347-53.

[21] Lange-Consiglio A, Corradetti B, Rutigliano L, Cremonesi F, Bizarro D. In vitro studies of horse umbilical cord matrix-derived cells: from characterization to labeling for magnetic resonance imaging. Open Tissue Eng Regen Med 2011;4:120-33.

[22] Paebst F, Piehler D, Brehm W, Heller S, Schroeck C, Tárnok A, et al. Comparative immunophenotyping of equine multipotent mesenchymal stromal cells: an approach toward a standardized definition. Cytometry 2014;85:678-87.

[23] Marycz K, Kornicka K, Basinska K, Czyrek A. Equine metabolic syndrome affects viability, senescence, and stress factors of equine adipose-derived mesenchymal stromal stem cells: new insight into EqASCs isolated from EMS horses in the context of their aging. Oxidative Med Cell Longev 2016: $1-17$.

[24] Niehage C, Steenblock C, Pursche T, Bornhaüser M, Corbeil D, Hoflack B. The cell surface proteome of human mesenchymal stromal cells. PLoS One 2011;6: $1-10$.

[25] Chen FM, Wu LA, Zhang M, Zhang R, Sun H. Homing of endogenous stem/ progenitor cells for in situ tissue regeneration: promises, strategies, and translational perspectives. Biomaterials 2011;32:3189-209.

[26] Huang L, Niu C, Willard B, Zhao W, Liu L, He W, et al. Proteomic analysis of porcine mesenchymal stem cells derived from bone marrow and umbilical cord: implication of the proteins involved in the higher migration capability of bone marrow mesenchymal stem cells. Stem Cell Res Ther 2015;6:1-18.

[27] Konala VBR, Mamidi MK, Bhonde R, Das AK, Pochampally R, Pasl R. The current landscape of the mesenchymal stromal cell secretome: a new paradigm for cell-free regeneration. Cytotherapy 2016;18:13-24.

[28] Quintanilha LF, Takami T, Hirose Y, Fujisawa K, Murata Y, Yamamoto N, et al Canine mesenchymal stem cells show antioxidant properties against thioacetamide-induced liver injury in vitro and in vivo. Hepatol Res 2014;44: 206-17.

[29] Ayatollahi M, Hesami Z, Jamshidzadeh A, Gramizadeh B. Antioxidant effects of bone marrow mesenchymal stem cell against carbon tetrachloride-induced oxidative damage in rat livers. Int J Org Transpl Med 2014;5(4):166-73.

[30] Soffler C. Oxidative stress. Vet Clin Equine 2013:23:135-57.

[31] Laskoski LM, Dittrich RL, Valadão CAA, Brum JS, Brandão Y, Brito HFV, et al. Oxidative stress in hoof laminar tissue of horses with lethal gastrointestinal diseases. Vet Immunol Immun 2016;171:66-72.

[32] Lee Y, El Andaloussi S, Wood MJ. Exosomes and microvesicles: extracellular vesicles for genetic information transfer and gene therapy. Hum Mol Genet 2012;15:125-34.

[33] Pascucci L, Alessandri G, Dall'Aglio C, Mercati F, Coliolo P, Bazzucchi C, et al Membrane vesicles mediate pro-angiogenic activity of equine adiposederived 111mesenchymal stromal cells. Vet J 2014;202:361-6.

[34] Lange-Consiglio A, Perrini C, Tasquier R, Deregibus MC, Camussi G, Pascussi L, et al. Equine amniotic microvesicles and their anti-inflamatory potential in a tenocyte model in vitro. Stem Cells Dev 2016;25:610-21.

[35] Perrini C, Strillacci MG, Bagnato A, Esposti P, Marini MG, Corradeti, et al. Microvesicles secreted from equine amniotic-derived cells and their potential role in reducing inflammation in endometrial cells in an in-vitro model. Stem Cell Res 2016;7:169-84. 